\title{
The age of onset of pubertal development in healthy Thai boys in Khon Kaen, Thailand
}

\author{
Noppol Kiatsopit ${ }^{\mathrm{a}}$, Ouyporn Panamonta ${ }^{\mathrm{a}}$, Chatchai Suesirisawat ${ }^{\mathrm{b}}$, Manat Panamonta ${ }^{\mathrm{a}}$ \\ ${ }^{a}$ Department of Pediatrics, Faculty of Medicine, Khon Kaen University, ${ }^{b}$ Khon Kaen Hospital, \\ Khon Kaen 40002, Thailand
}

\begin{abstract}
Background: There is variation of the age of onset of puberty in a population. The secular trends in the timing of pubertal development have decreased in some parts of the world.

Objective: To determine the age of pubertal development in healthy Thai boys in Khon Kaen, Thailand and compare it with that in previous studies of Thai boys.

Methods: A descriptive, cross-sectional study was performed in 316 school boys aged 5-16 years between May and July 2011. Development of the genitals and pubic hair was determined by Tanner staging, and testicular volume was assessed using a Prader orchidometer. All boys were examined by a male pediatrician.

Results: Genital stage of puberty in boys occurred at a median age of 11.3 years and a mean \pm SD age of $11.3 \pm 1.3$ (mean \pm SD, range 8.0-14.9) years, and pubarche occurred at a median age of 12.8 years and a mean \pm SD of $12.5 \pm 1.2$ years (range $9.1-14.9$ ) years.

Conclusions: No secular trend towards earlier age at pubertal onset for gonadarche in Khon Kaen boys, but pubarche seems to be later than found in previous studies in Thai boys.
\end{abstract}

Keywords: Gonadarche, pubarche, pubertal development, secular trends, Thai boy

The age of onset of puberty varies between ethnic groups and depends on genetic and environmental factors. Normally girls enter puberty approximately two years earlier than boys. The normal ranges of pubertal onset came from the studies of British children from the 1960s by Tanner and Marshall $[1,2]$. Based on these studies, the traditional cut-offs for precocious puberty are development of secondary sex characteristics before the age of 9 years in boys and 8 years in girls. Enlargement of the testes (gonadarche) is the first sign of pubertal development in boys. Pubic hair (pubarche) often appears on a boy after gonardarche begins. Only few data on pubertal development in Thai boys have been reported and the last from Bangkok, the capital of Thailand, which was reported more than one decade ago [3, 4]. To our knowledge, there were no data yet available for Thai children from the northeast of Thailand. This study was therefore performed to determine the timing of onset of puberty and the ages at various Tanner

Correspondence to: Ouyporn Panamonta, Pediatric Endocrinology Unit, Department of Pediatrics, Srinagarind Hospital, Khon Kaen University, Khon Kaen 40002, Thailand. E-mail: ouypan@kku.ac.th stages of pubertal development in healthy Thai boys in Khon Kaen, northeast Thailand.

\section{Materials and methods}

Between May and July 2011, a cross-sectional prospective study of the sexual maturation of healthy Thai boys was conducted in primary and secondary schools in Khon Kaen, northeast Thailand. All boys were Thai aged 8 to 16 years. Genital $(G)$ and pubic hair $(\mathrm{PH})$ maturity were assessed by well-trained male pediatricians and graded according to the 5-stage scales described by Marshall and Tanner (Table 1). Testicular size or volume was assessed using a Prader orchidometer and reported in milliliters $(\mathrm{mL})$. The testicular volume of $1-3 \mathrm{~mL}$ was genital stage $\mathrm{G} 1$, 4-9 mL was G2, 10-14 mL (G3), 15-20 mL (G4), and greater than $20 \mathrm{~mL}$ was G5. At the examinations, measurements of weight and height were also recorded. The exclusion criteria encompassed underlying chronic systemic diseases, which effect sex development, history of steroid usage or any drugs that have effects on growth and pubertal development. The study was approved by the Ethics Committee of the Faculty of Medicine, Khon Kaen University. Written informed consent was obtained from all parents and assent from the boys. 
Table 1. Tanner stage in boys (adapted from [2])

\begin{tabular}{cll}
\hline Tanner stages & \multicolumn{1}{c}{ Genitalia (G) } & \multicolumn{1}{c}{ Pubic hair (PH) } \\
\hline 1 & Preadolescent & No coarse, pigmented hair \\
2 & $\begin{array}{l}\text { Testicular size } 4-9 \mathrm{~mL} \text {, skin on scrotum thin, reddens } \\
\text { and enlarges, earliest increased penile length and width }\end{array}$ & $\begin{array}{l}\text { Minimal coarse, pigmented hair at base } \\
\text { of penis }\end{array}$ \\
3 & Testicular size 10-14 mL, further enlarged scrotum & $\begin{array}{l}\text { More coarse and curly, begins to extend } \\
\text { laterally }\end{array}$ \\
4 & $\begin{array}{l}\text { Testicular size 15-20 mL, further enlarged and darken } \\
\text { scrotum, penis increases in length to } 10 \mathrm{~cm} \text { and width }\end{array}$ & $\begin{array}{l}\text { Adult-like, extending across pubis but } \\
\text { sparing medial thighs }\end{array}$ \\
5 & $\begin{array}{l}\text { Testicular size }>20 \mathrm{~mL} \text {, adult scrotum and penile } \\
\text { length of } 15 \mathrm{~cm}\end{array}$ & Extends to medial surface of thighs \\
\hline
\end{tabular}

\section{Statistical analysis}

The distribution of the onset of puberty at various stages by Probit analysis was estimated. Data analyses were performed by using STATA version 7.0 and reported in maximum, minimum, median, mean, 95\% confidence interval (CI) and standard deviations (SD). A Student $t$ test was used to compare potential difference of ages at onset of puberty with the previous studies and $P<0.05$ was considered significant.

\section{Results}

Nine hundred school boys were invited to join the study and 320 boys participated. Of the 320 boys, 4 boys were excluded; 2 were foreigners and 2 regularly used inhaled corticosteroids. There were 316 boys enrolled in the study, all had good physical and mental health. The data of the mean weight, height, and BMI were categorized by age groups in Table 2 . Tables 3 and 4 shows the median and mean ages at various stages of puberty. The median and the mean \pm SD ages of the onset of genital stages (gonadarche, G2) were 11.3 and $11.3 \pm 1.3$ years respectively. Five (7\%) boys had testicular volumes of $4 \mathrm{~mL}$ or greater before the age of 9 years. The median and the mean \pm SD ages of the onset of pubic hair stages (pubarche, PH2) were 12.8 and $12.5 \pm 1.2$ years. Not one of the boys developed pubic hair before the age of 9 years. Comparison of the ages of onset of puberty between the present and the previous studies in Thai boys are shown in Table 5 . There was a statistically significant difference of the mean age of PH2 between the previous studies and this study. Figure 1 shows the range and mean ages for each pubertal stage.

Table 2. Mean \pm SD of height, weight and BMI of 316 boys

\begin{tabular}{lllll}
\hline Age(year) & Number & $\begin{array}{l}\text { Height }(\mathbf{c m}) \\
\text { Mean } \pm \text { SD }\end{array}$ & $\begin{array}{l}\text { Weight }(\mathbf{k g}) \\
\text { Mean } \pm \text { SD }\end{array}$ & $\begin{array}{l}\text { BMI(kg/m²) } \\
\text { Mean } \pm \text { SD }\end{array}$ \\
\hline $8-8.9$ & 30 & $129.0 \pm 5.1$ & $30.5 \pm 8.4$ & $18.2 \pm 4.2$ \\
$9-9.9$ & 42 & $133.3 \pm 6.7$ & $34.4 \pm 9.5$ & $19.2 \pm 4.5$ \\
$10-10.9$ & 41 & $138.1 \pm 8.0$ & $36.8 \pm 9.9$ & $19.1 \pm 3.9$ \\
$11-11.9$ & 62 & $148.6 \pm 6.8$ & $44.2 \pm 11.0$ & $19.8 \pm 3.9$ \\
$12-12.9$ & 39 & $151.8 \pm 8.9$ & $48.5 \pm 15.5$ & $20.6 \pm 5.0$ \\
$13-13.9$ & 58 & $158.7 \pm 8.8$ & $49.6 \pm 13.6$ & $19.4 \pm 4.0$ \\
$14-14.9$ & 35 & $165.3 \pm 7.9$ & $55.3 \pm 16.4$ & $20.0 \pm 5.0$ \\
$15-15.9$ & 9 & $167.3 \pm 4.3$ & $53.1 \pm 4.3$ & $19.0 \pm 1.6$ \\
Total & 316 & $148.0 \pm 14.1$ & $43.6 \pm 14.4$ & $19.5 \pm 4.3$ \\
\hline
\end{tabular}


Table 3. Ages at 5 genital (G) stages in 316 school boys

\begin{tabular}{cccccc}
\hline Tanner stage & Number & $\begin{array}{c}\text { Mean } \pm \text { SD } \\
\text { (years) }\end{array}$ & $\begin{array}{c}\text { Median } \\
\text { (years) }\end{array}$ & $\begin{array}{c}\text { Range } \\
\text { (years) }\end{array}$ & 95\%CI of mean age (years) \\
\hline G1 & 70 & $9.3 \pm 0.8$ & 9.3 & $8.0-11.7$ & $9.1-9.5$ \\
G2 & 118 & $11.3 \pm 1.3$ & 11.3 & $8.0-14.9$ & $11.0-11.5$ \\
G3 & 34 & $12.8 \pm 1.1$ & 12.7 & $11.3-14.6$ & $12.4-13.1$ \\
G4 & 77 & $13.5 \pm 1.0$ & 13.5 & $11.0-15.8$ & $13.2-13.7$ \\
G5 & 17 & $14.5 \pm 0.9$ & 14.9 & $11.7-15.7$ & $14.1-15.0$ \\
Total & 316 & $11.7 \pm 2.0$ & 11.7 & $8.0-15.8$ & $11.5-11.9$ \\
\hline
\end{tabular}

Table 4. Age at pubic hair (PH) development in 316 school boys

\begin{tabular}{lccccc}
\hline Tanner stage & Number & $\begin{array}{c}\text { Mean } \pm \text { SD } \\
\text { (year) }\end{array}$ & $\begin{array}{c}\text { Median } \\
\text { (year) }\end{array}$ & $\begin{array}{c}\text { Range } \\
\text { (year) }\end{array}$ & $\begin{array}{c}\text { 95\% CI of mean } \\
\text { age (year) }\end{array}$ \\
\hline PH1 & 166 & $10.3 \pm 1.3$ & 10.2 & $8.0-13.8$ & $10.1-10.5$ \\
PH2 & 52 & $12.5 \pm 1.2$ & 12.8 & $9.1-14.9$ & $12.2-12.8$ \\
PH3 & 47 & $13.2 \pm 1.0$ & 13.5 & $11.0-14.7$ & $12.9-13.5$ \\
PH4 & 36 & $13.8 \pm 0.9$ & 13.7 & $11.7-15.8$ & $13.5-14.1$ \\
PH5 & 15 & $14.8 \pm 0.4$ & 14.9 & $13.7-15.7$ & $14.5-15.0$ \\
Total & 316 & $11.7 \pm 2.0$ & 11.7 & $8.0-15.8$ & $11.5-11.9$ \\
& & & & & \\
\hline
\end{tabular}

Table 5. Ages (years) of onset of genital (G) and pubic hair (PH) development in Thai boys, comparison between the present and previous studies

\begin{tabular}{lccccc}
\hline Year & $\begin{array}{c}\text { Age (y) } \\
\text { of subjects }\end{array}$ & $\begin{array}{c}\text { Number } \\
\text { of subjects }\end{array}$ & $\begin{array}{c}\text { Assessment } \\
\text { of puberty }\end{array}$ & $\begin{array}{c}\text { Mean ages (y) } \\
\text { of G2 }\end{array}$ & $\begin{array}{c}\text { Mean ages (y) } \\
\text { of PH2 }\end{array}$ \\
\hline $1997-1999^{4}$ & $7-15$ & 94 & Self & $11.3 \pm 1.7 *$ & $12.2 \pm 1.3 * *$ \\
$1997-1999^{3}$ & $9-18$ & 300 & Pediatrician & $11.3 \pm 0.8 *$ & $12.2 \pm 0.4 * * *$ \\
2011 & $8-16$ & 316 & Pediatrician & $11.3 \pm 1.3$ & $12.5 \pm 1.2$ \\
\hline
\end{tabular}

$* P>0.999,{ }^{* *} P=0.0375, * * * P<0.001$

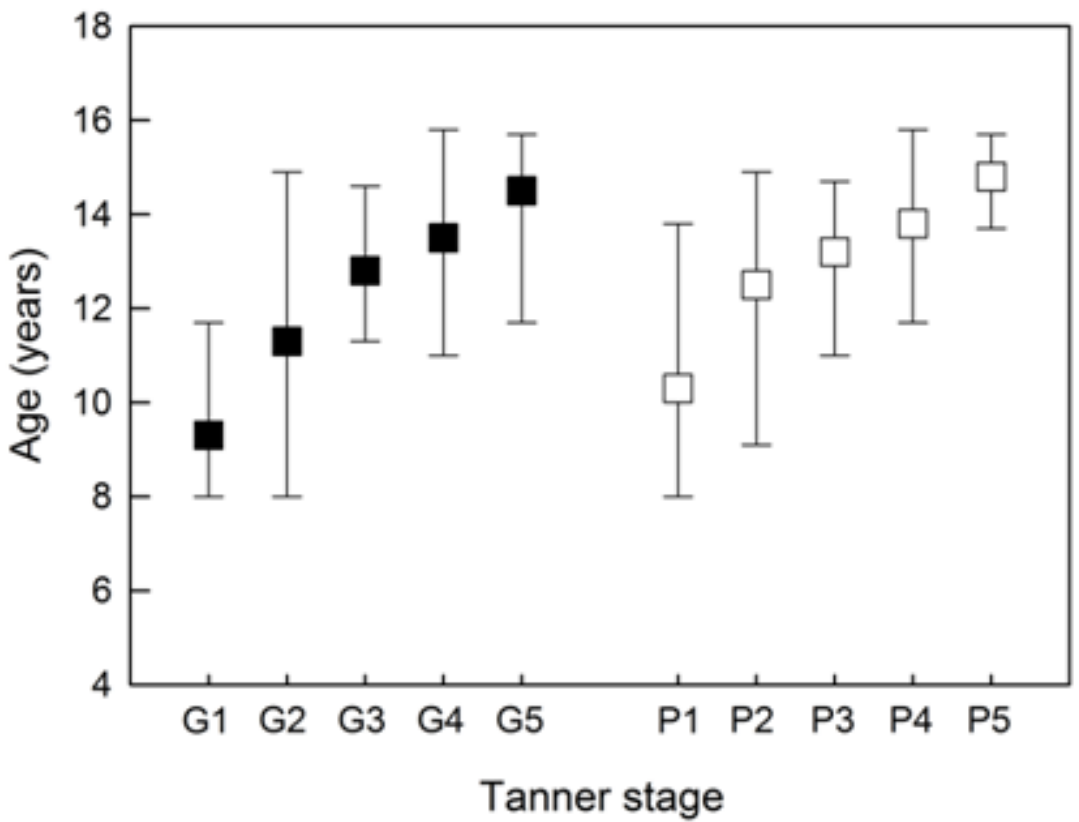

Figure 1. The range and mean ages of various Tanner pubertal stages of 316 boys. Genital $(\mathrm{G})$ and pubic hair $(\mathrm{P})$. 


\section{Discussion}

The age of onset of puberty is determined by genetic factors, geographic locations, socioeconomic factors and nutritional status. The secular trend to earlier pubertal maturation was observed especially in girls [5-8], possibly because of improved nutrition and increased socioeconomic status that corresponded with the markedly increased prevalence of obesity in Thai school children in the recent years [9]. In girls, earlier age at menarche was reported after exposure to many endocrine disrupters such as polychlorinated biphenyls (PCBs), polybrominated biphenyls, pesticides-dichlorodiphenyltrichloroethane (DDT), and phthalate esters. In boys, exposure to PCBs and pesticides was associated with delayed puberty or decreased penile length [10]. There are few studies of the timing of puberty in boys $[3,4,7,11,12]$. This is probably because boys may refuse examination of their genitalia or it may be because of less interest in male puberty reflecting less cultural awareness of male pubertal development compared with girls [4, 7]. There was little change in the timing of the onset of puberty in boys both in gonadarche and pubarche $[7,12]$. Data for genital and pubic hair development in US during 1940 to 1994 are insufficient to suggest a trend towards an earlier puberty in boys because orchidometry was not performed in any of the US population-based studies [7]. In general, no marked secular trend towards earlier age at pubertal onset in boys was evident from the mid-1960s to the late 1990s $[12,13]$. The largest pubertal study in boys $(n=18,807)$ was conducted in an Asian country, China between 2003 and 2005 [14]. Using a cut-off of testicular volume of $4 \mathrm{~mL}$, they found that the onset of puberty is at a median age of 10.55 years, which was earlier than most of European boys. Moreover 12.99\% of urban Chinese boys had testicular volume of $4 \mathrm{~mL}$ or greater even before the age of 9 years. The previous study in Thai boys who lived in Bangkok during 1997 to 1999 suggested that the mean age of onset of puberty and pubarche were 11.3 and 12.2 years [3, 4]. However, some data were obtained from children by self-assessment using photographs of Tanner stages and early pubic hair and exact testicular volumes would not have been detectable. Moreover boys have a tendency to underestimate their genital and pubic hair stage in the advanced stage compared with those in early stage of puberty $[4,15]$. The present study showed that the onset of gonadarche is at a mean age of 11.3 years with the range of 8.0-14.9 years and only 5 (7\%) Thai boys had testicular volume of $4 \mathrm{~mL}$ or greater even before the age of 9 years. The onset of pubarche was found to be at 12.5 years with the range of 9.1-14.9 years and no boy in this study developed pubic hair before 9 years. The secular trend for the age of onset of gonadarche of Khon Kaen boys was not changed, but the age at pubarche was slightly later. The Lawson Wilkins Pediatric Endocrine Society issued the recommendations for the age at which puberty should be considered precocious at before 9 years in Caucasian boys [16]. The Thai Society of Pediatric Endocrinology also use the cut-off at 9 years for precocious puberty in Thai boys, therefore recommendations for the age at which puberty should be considered precocious remained unchanged for boys from Khon Kaen.

\section{Conclusion}

The age of onset of pubertal development in healthy Thai boys in Khon Kaen was not changed from the previous studies for gonadarche, but pubarche seems to be later.

\section{Acknowledgements}

This study was granted by Faculty of Medicine, Khon Kaen University, Thailand (Grant Number I 54118). We wish to acknowledge the support of the Khon Kaen University Publication Clinic, Research and Technology Transfer Affairs, Khon Kaen University, for their assistance. The authors have no conflict of interest to declare.

\section{References}

1. Marshall WA, Tanner JM. Variations in patterns of pubertal changes in girls. Arch Dis Child. 1969; 44: 291-303.

2. Marshall WA, Tanner JM. Variations in patterns of pubertal changes in boys. Arch Dis Child. 1970; 45: 13-23.

3. Mahachoklertwattana P, Suthutvoravut U, Poomthavorn P, Charoenkiatkul S, Udomsubpayakul U, Rajatanavin R. Sexual maturation in Thai boys. J Pediatr Endocrinol Metab. 2010; 23:65-71.

4. Wacharasindhu S, Pri-Ngam P, Kongchonrak T. Selfassessment of sexual maturation in Thai children by Tanner photograph. J Med Assoc Thai. 2002; 85: 308-19.

5. Russo G, Brambilla P, Della Beffa F, Ferrario M, Pitea M, Mastropietro T, et al. Early onset of puberty in young girls: an Italian cross-sectional study. J 
Endocrinol Invest. 2012; 35:804-8.

6. Ma HM, Du ML, Luo P, Chen SK, Liu L, Chen RM, et al. Onset of breast and pubic hair development and menses in urban Chinese girls. Pediatrics. 2009; 124:e269-77.

7. Euling SY, Herman-Giddens ME, Lee PA, Selevan SG, Juul A, Sorensen TIA, et al. Examination of US puberty-timing data from 1940 to 1994 for secular trends: panel findings. Pediatrics. 2008; 121:(Suppl 3): 171-91.

8. Jirawutthinan N, Panamonta O, Jirawutthinan S, Suesirisawat C, Panamonta M. The age of onset of pubertal development in healthy Thai girls in Khon Kaen, Thailand. Asian Biomed. 2012; 6:859-65.

9. Panamonta O, Thamsiri N, Panamonta M. Prevalence of type II diabetes and metabolic syndrome among overweight school children in Khon Kaen, Thailand. J Med Assoc Thai. 2010; 93:56-60.

10. Den Hond E, Schoeters G. Endocrine disrupters and human puberty. Int J Androl. 2006; 29:264-71.

11. Biro FM, Lucky AW, Huster GA, Morrison GA.
Pubertal staging in boys. J Pediatr. 1995; 127:100-2.

12. Mul D, Fredriks AM, van Buuren S, Oostdijk W, Verloove-Vanhorick SP, Wit JM. Pubertal development in the Netherlands 1965-1997. Pediatr Res. 2001; 50: 479-86.

13. Juul A, Teilmann G, Scheike T, Hertel NT, Holm K, Laursen EM, et al. Pubertal development in Danish children: comparison of recent European and US data. Int J Androl. 2006; 29:247-55.

14. Ma HM, Chen SK, Chen RM, Zhu C, Xiong F, Li T, et al. Pubertal development timing in urban Chinese boys. Int J Androl. 2011; 34:e435-45.

15. Boas SR, Falsetti D, Murphy TD, Orenstein M. Validity of self-assessment in adolescent male patients with cystic fibrosis. J Adol Health. 1995; 17:42-5.

16. Carel JC, Eugster EA, Rogol A, Ghizzoni L, Palmert MR, on behalf of the members of the ESPE-LWPES GnRH Analogs Consensus. Consensus statement on the use of gonadotropin-releasing hormone analogs in children. Pediatrics. 2009; 123:e752-62. 